DOCTRINA

\title{
El Consejo de Seguridad de la Naciones Unidas, los regímenes de sanciones y la experiencia argentina
}

\author{
The UN Security Council, the sanctions regimes and the Argentinean experience
}

\author{
Fernando Rolandelli \\ Universidad Católica Argentina Santa María de los Buenos Aires, Argentina
}

\begin{abstract}
RESUMEN La posición argentina de política exterior relativa a la lucha contra el terrorismo es de absoluto respeto por los derechos humanos y de enmarcarse en la multilateralidad institucional organizada, es decir, dentro del marco de las Naciones Unidas - $\mathrm{o}$ de organizaciones regionales como la OEA o el Mercosur-. De este modo, Argentina solamente acepta y reconoce listados de sanciones por actividades relacionadas con el terrorismo y su financiación elaborados por el Consejo de Seguridad de la ONU, sin tener un listado propio, ni reconocer listados de naciones individuales o grupos de naciones. Sin embargo, el hecho de haber sido el país de la región que ha sufrido los dos mayores atentados a manos del terrorismo globalizado después de los Estados Unidos, ambos reivindicados por el brazo armado de la organización libanesa Hezbollah, gran parte de su sociedad y la comunidad internacional esperaban un mayor involucramiento, especialmente al cumplirse los 25 años del atentado contra la sede de la AMIA. En consecuencia, se creó el Registro de Personas y Entidades Vinculadas a Actos de Terrorismo y su Financiamiento (RePET), el que no solo es una solución de compromiso político, sino que también tiene ventajas prácticas al incrementar la transparencia y visibilidad del sistema.
\end{abstract}

PALABRAS CLAVE Terrorismo, listados, sanciones, Consejo de Seguridad.

ABSTRACT Argentina's foreign policy position regarding the fight against terrorism is one of absolute respect for human rights and of being framed within organized institutional multilateralism, that is, within the framework of the United Nations - or regional organizations such as the OAS or the Mercosur. Thus, Argentina only accepts and recognizes lists of sanctions for activities related to terrorism and its financing prepared by the UN Security Council, without having its own list, nor recognizes lists of individual nations or groups of nations. However, the fact of having been the country in the region that has suffered the two largest attacks at the hands of globalized terrorism after the United States, both claimed by the armed wing of the Lebanese organization Hezbollah, 
a large part of its society and the international community hoped for greater involvement, especially on the 25th anniversary of the attack on the AMIA headquarters. Consequently, the Registry of Persons and Entities Linked to Terrorism and its Financing (RePET) was created, which constituted a solution of political compromise, but also has practical advantages by increasing the transparency and visibility of the system.

KEYWORDS Terrorism, lists, sanctions, Security Council.

\section{Introducción}

Argentina creó el Registro Público de Personas y Entidades Vinculadas a Actos de Terrorismo y su Financiamiento (RePET) el 16 de julio de 2019, por el Decreto 489. Su creación fue anunciada públicamente durante la Segunda Conferencia Ministerial Hemisférica de Lucha contra el Terrorismo por el entonces ministro de Justicia, Dr. Garavano. La fecha no podía ser más significativa, puesto que se cumplían 25 años del atentado contra la sede de la Asociación Mutual Israelita Argentina (AMIA) en Buenos Aires, reivindicada por el brazo armado de la organización libanesa Hezbollah, segundo de los dos ejecutados en rápida sucesión, ${ }^{1}$ contra la embajada de Israel en Buenos Aires² en 1992 y a AMIA³ en 1994 (Corach y Baizán, 2002).

La Conferencia misma se producía en medio de las tensiones entre Estados Unidos e Irán, ${ }^{4}$ tradicional apoyo de esa organización, ${ }^{5}$ que conllevaban fuertes presiones diplomáticas ${ }^{6}$ por parte del primero a sus aliados regionales, a fin de adoptar medidas que permitieran su tratamiento como entidad terrorista, las que incluían la creación de sistemas de «listados» de personas y entidades terroristas nacionales. La posición

1. Estos fueron los atentados más importantes —en realidad, los únicos- que se dieron en la región hasta la destrucción de las Torres Gemelas por parte del terrorismo trasnacional o globalizado.

2. El 17 de marzo de 1992, un ataque terrorista a la embajada de la República de Israel en Argentina causó la muerte de 29 personas, varias decenas de heridos y destruyó completamente la sede de la embajada y del consulado. A las 14:45, un furgón conducido por un terrorista suicida fue cargado con explosivos y estrellado contra el frente del edificio.

3. Ocurrido el lunes 18 de julio de 1994, cuando una bomba estalló en la sede de la Asociación Mutual Israelita Argentina (AMIA), en la ciudad de Buenos Aires, demoliendo el edificio y dañando seriamente los inmuebles cercanos, lo cual causó la muerte de 85 personas y más de 300 heridos.

4. Véase, por ejemplo, Katzman (2020).

5. Sobre el particular, véase Levitt (2021).

6. Incluyendo, por supuesto, la creación de la serie de Conferencias Hemisféricas de Lucha contra el Terrorismo, la primera de las cuales se llevó a cabo en Washington en diciembre de 2019, y en la que se obtuvo el compromiso argentino de ser sede de la segunda edición. Esta conferencia hizo levantar las cejas de la Secretaría Ejecutiva de la Convención Interamericana Contra el Terrorismo de la OEA (CICTE), Alison Treppel, quien con cierta lógica sintió que su organización, que era el espacio multilateral natural de la región en la temática, quedaba de lado. 
de Argentina de política exterior en la materia, incluso tras haber sido víctima de dos ataques a manos del terrorismo internacional, fue siempre la de mantener la lucha contra ese flagelo en el contexto del multilateralismo institucionalizado, lo cual la ha llevado a reconocer únicamente los listados provenientes de los Comités de Sanciones del Consejo de Seguridad de las Naciones Unidas y a desestimar la creación de un sistema de listados propios.

El propósito de este trabajo es presentar una institución política novedosa, que se dio como una solución ingeniosa al problema de la necesidad de contar con un mecanismo nacional de listado de personas vinculadas al terrorismo o su financiación, sin crear un marco legal que permitiera la «designación» de una persona como «terrorista» por una autoridad del Ejecutivo, lo que se podría prestar al abuso o arbitrariedad y eventualmente vulnerar derechos humanos. Al mismo tiempo, responde a la necesidad y voluntad política de mostrar un liderazgo regional en la lucha contra el terrorismo globalizado, máxime si consideramos que Argentina ha sido víctima de ataques en dos oportunidades, y de satisfacer a una parte de la opinión pública que muestra indignación y frustración ante la aparente imposibilidad de obtener justicia contra los supuestos autores, sin por ello vulnerar la sensibilidad de esa población ante los abusos de autoridad ocurridos en la represión de todo tipo de protesta social en los años setenta, en lo que ha dado en llamarse «terrorismo de Estado», y que llevó a múltiples violaciones de los derechos humanos. Al mismo tiempo, da publicidad y consolida la internalización de los listados relevantes del Consejo de Seguridad.

A tal fin, describiremos breve y sucintamente el régimen de los Comités de Sanciones del Consejo de Seguridad de ONU en su parte relevante, ${ }^{7}$ pasando luego a hacer lo mismo con las organizaciones y países que han sancionado mecanismos propios de designación. Luego describiremos el sistema argentino en mayor detalle, contraponiéndolo conceptualmente a los anteriores.

\section{El Consejo de Seguridad de la Organización de Naciones Unidas y el terrorismo}

La Resolución $1.373(2001)^{8}$ es la «madre» de todo el sistema actual de lucha contra el terrorismo globalizado del CSNU. Dictada en el marco de sus atribuciones por el capítulo 7 de la Carta, sus disposiciones son obligatorias para los Estados. Declara al terrorismo internacional una amenaza a la paz y la seguridad internacionales e invoca el derecho inmanente de legítima defensa individual o colectiva de la Carta. En ella

7. No es el propósito y cae bien fuera del marco de este trabajo una exposición acerca de este mecanismo, que merece uno - o varios, dadas sus muchas aristas - trabajo específico.

8. Aprobada por el CSNU en su $4 \cdot 385 .^{\text {a }}$ sesión, celebrada el 28 de septiembre de 2001, inmediatamente posterior a los ataques del 11 de septiembre de 2001. 
sienta las bases de la cooperación de los Estados en la lucha contra el terrorismo y su financiación, por medio de normas internas que tipifiquen como delito esta última en cualquier forma y dispongan el congelamiento de fondos de las personas participantes; que repriman todo tipo de apoyo incluyendo el reclutamiento y el abastecimiento de armas. Asimismo, contiene disposiciones muy duras respecto del instituto del refugio y su aprovechamiento por terroristas y su utilización del territorio de un Estado en la comisión de actos terroristas en el territorio de otro. Asimismo, se establecen las bases de la obligación de los Estados de cooperar y coordinar sus acciones por medio del intercambio de información operacional, y cooperar en las esferas administrativas y judiciales, incluyendo la adhesión a los convenios y protocolos pertinentes (párrs. 1, 2 y 3, Resolución CSNU 1.373, 2001).

Finalmente, crea un comité formado por todos los miembros del Consejo para verificar su aplicación, y exhorta a los Estados a informar al Consejo sobre las medidas tomadas para la aplicación de la Resolución. Este es el germen del Comité contra el Terrorismo (CTC) y su órgano ejecutivo, el Counter Terrorism Executive Directorate (CTED).

\section{Los regímenes de sanciones}

La finalidad de las sanciones obligatorias es ejercer presión sobre un Estado o entidad para que respete los objetivos fijados por el Consejo de Seguridad sin recurrir al uso de la fuerza. ${ }^{9}$

Para el Consejo de Seguridad, las sanciones son un instrumento importante para hacer cumplir sus decisiones. ${ }^{10}$ El primer tipo de sanciones, contra Estados, eran no discriminatorias y se denominan comprensivas. ${ }^{11}$ Las sanciones más modernas pueden llamarse dirigidas, al estarlo específicamente contra individuos o entidades dentro un Estado, minimizando los efectos adversos en la población civil (Cortright y López, 1995, 2002), posibles gracias a la consolidación de la responsabilidad internacional individual (Cortright y López, 2002; Biersteker, Eckert y Tourinho, 2016). Al estar dictadas por el Consejo de Seguridad en virtud de sus atribuciones del capítulo 7 de la Carta, resultan especialmente apropiadas para hacer respetar sus decisiones cuando se ha puesto en peligro la paz y seguridad internacionales, y ha fracasado la vía

9. «Comités, grupos de trabajo y órganos especiales», Consejo de Seguridad de la ONU, disponible en https://bit.ly/32vI3nl.

10. La bibliografía general sobre el Consejo de Seguridad de las Naciones Unidas es por demás extensa, y no es el propósito de este trabajo ahondar en esta institución. Véase, por ejemplo, Byers (2001) y Chiletto y Quiroga (2018).

11. La más antigua conocida es la tomada por Atenas contra Megara, prohibiéndole comerciar con cualquier integrante de la Liga de Delos (Tsebelis, 1990; Cortright y López, 2000). 
diplomática. Hay sanciones generales de tipo económico y comercial, y otras más específicas, como el embargo de armas, la prohibición de viajar o las restricciones financieras o diplomáticas.

De esta manera, las sanciones del Consejo de Seguridad han adoptado formas diversas en función de los objetivos que se perseguían. Han ido de amplias sanciones económicas y comerciales a medidas más selectivas, como embargos de armas, prohibiciones de viajar y restricciones financieras o de determinados productos (Giume1li, 2011; Biersteker, Eckert y Tourinho, 2016).

El Consejo de Seguridad ha aplicado sanciones para prestar apoyo a las transiciones pacíficas, disuadir de la implantación de cambios no constitucionales, poner coto al terrorismo, proteger los derechos humanos y promover la no proliferación de las armas nucleares. Desde 1966 se han aplicado 30 regímenes de sanciones diversos; muchos de ellos han caducado y existen hoy 14, cada uno con un comité especial y apoyado por un grupo o equipo especial de seguimiento en 11 casos. ${ }^{12}$

El mecanismo de los regímenes de sanciones resulta particularmente apropiado para la lucha contra el terrorismo globalizado. Los dos pilares de todo régimen son, por un lado, las sanciones en $\operatorname{sí}^{13} \mathrm{y}$ un listado designando las personas a las cuales se aplica, por el otro. Todo régimen tiene un procedimiento a seguir a fin de incluir a individuos, ${ }^{14}$ grupos o entidades, y también para su supresión. ${ }^{15}$

Los Comités relacionados con el terrorismo originarios fueron los creados por la Resolución 1.267 (1999) relativa al Talibán, y por la Resolución 1.333 (2000), relativa a Al-Qaida. Posteriormente, la Resolución 1.989 (2011) dividió la «Lista consolidada de

12. «Comités...».

13. Que por supuesto varían según la circunstancia que motivó la creación del régimen de sanciones. Las habituales son el congelamiento de activos, el embargo de armas (entendido como «suministro de armas y equipo militar») y la prohibición de viaje. Pero también hay sanciones específicas a la situación particular contemplada; por ejemplo, las dispuestas por la Resolución 751 (1996) sobre Somalia incluyen la prohibición de importar o exportar carbón vegetal desde o hacia su territorio.

14. Habitualmente a pedido de un Estado miembro, e incluye, en el caso que nos ocupa, un punto focal para las solicitudes de supresión de las listas y una Oficina del Ombudsman; esto, a fin de asegurar el respeto por los derechos de las personas y entidades cuya inclusión se solicita.

15. El respeto por los derechos humanos se vio incrementado con la creación de la institución del ombudsman: «La Oficina del Ombudsman se estableció en virtud de la Resolución 1.904 (2009) del Consejo de Seguridad. Su mandato se prorrogó mediante la Resolución 1.989 (2011), la Resolución 2.083 (2012), la Resolución 2.161 (2014), la Resolución 2.253 (2015) y la Resolución 2.368 (2017). El mandato actual vence el 17 de diciembre de 2021. Las personas, los grupos, las empresas o las entidades que deseen ser excluidos de la Lista de Sanciones contra el EIIL (Dáesh) y Al-Qaida del Consejo de Seguridad pueden enviar su solicitud de exclusión a un ombudsman independiente e imparcial nombrado por el Secretario General». «La Oficina del Ombudsman del Comité de Sanciones contra el EIIL (Dáesh) y Al-Qaida», Consejo de Seguridad de la ONU, disponible en https://bit.ly/3JmpK4B. Véase también Bermejo García (2013). 
personas y entidades asociadas con los talibanes y Al-Qaida», en dos listas, a fin de reflejar los acuerdos de reconciliación nacional entre el entonces gobierno nacional afgano y el Talibán. ${ }^{16}$ Finalmente, la Resolución 2.253 (2015) amplió la lista de AlQaida a fin de incluir al Estado Islámico en el Iraq y el Levante (EIIL, ISIS en inglés), también conocido como Daesh. Además de estas organizaciones, toda persona, grupo o entidad incluida en la lista correspondiente es reconocida («designada») como «terrorista» en algún grado de participación. ${ }^{17}$ Esta «designación», al ser realizada por el Consejo de Seguridad en sus funciones del capítulo 7 de la Carta, reviste carácter vinculante y universal.

\section{Los regímenes de sanciones o «listados» nacionales}

La dificultad de lograr que ciertas entidades u organizaciones sean listadas como terroristas por el Consejo de Seguridad — al ser una medida tomada en virtud del capítulo 7 , está sujeta a derecho de veto y, por lo tanto, a una evaluación política- ${ }^{18}$ ha motivado que muchos países hayan recurrido a la creación de listados nacionales.

A su vez, existe un reconocimiento de que la efectiva implementación de sanciones requiere de la actividad de los Estados; las organizaciones internacionales carecen de los mecanismos para asegurarla (Cohen y Goldman, 2019). En efecto, la implementación de un régimen de sanciones involucra una ingente actividad administrativa y legislativa de múltiples agencias estatales, como también de los tribunales, en cuanto a cumplimiento de la ley, recolección de inteligencia y procesamientos penales. Estas actividades caen dentro de la órbita de la soberanía estatal, por lo que la implementación de los regímenes de sanciones establecidos por cualquier organización internacional, incluida la ONU, recaerá necesariamente en los Estados nacionales.

Al presente, los Estados Unidos basan sus facultades de designar a individuos y entidades como «terroristas» en la Orden Ejecutiva 13.224, firmada por el entonces presidente George W. Bush el 23 de septiembre de 2001. En ella, faculta a la Secretaría de Estado, en conjunto con la Secretaría del Tesoro y el Procurador General, a designar como tales a individuos o entidades, ${ }^{19}$ previa intervención de la Oficina del Coordinador Contra Terrorismo (S/CT) y posterior informe al Congreso. Para enti-

16. Acuerdo de Bonn (2001), la Conferencia de Londres (2010) y la Conferencia de Kabul (2010), como expresamente se mencionan en el sexto párrafo preambular de la Resolución 1.988 (2011).

17. Existe un listado por cada Comité. También un «listado consolidado» que incluye a todas las personas, grupos o entidades incluidos en cualquier comité y que ha originado alguna confusión respecto de su condición de «vinculadas al terrorismo».

18. Sin contar, por supuesto, las críticas de la academia. Véase, por ejemplo, el trabajo de Andrew Hudson (2007). Véase, también, Consejo Noruego para los Refugiados NRC y OCHA (2018).

19. La Orden Ejecutiva original incluía a 29 personas y entidades designadas en el mismo momento de su firma. 
dades extranjeras exclusivamente rige la Immigration and Nationality Act (INA) de $1965 .{ }^{20}$ Los criterios, ${ }^{21}$ procedimientos, autoridades involucradas y efectos de ambos sistemas son similares. Los efectos son básicamente un bloqueo de activos y transacciones; ambas apuntan al apoyo y financiamiento de las organizaciones terroristas. La designación es pública y existe un Registro Federal. Puede ser impugnada por el interesado a los dos años de presentada.

La Unión Europea, por su parte, estableció en diciembre de 2001 una lista de personas, grupos y entidades implicados en actos terroristas y sujetos a medidas restrictivas, como parte de su respuesta contra el terrorismo tras los atentados del 11 de septiembre de ese mismo año. ${ }^{22}$ Este régimen, fijado en la Posición Común 2001/931/ PESC, es diferente del régimen de la Unión Europea por el que se aplica la Resolución 1.989 (2011) del Consejo de Seguridad de las Naciones Unidas sobre la congelación de capitales de personas y entidades asociadas a Osama bin Laden, la red Al-Qaeda y los talibanes (incluido el EIIL/Daesh). Además, la Unión Europea ha sancionado una directiva del Parlamento y Consejo europeos relativa a la lucha contra el terrorismo, del 15 de marzo de 2017.23 La Unión Europea - y algunos de sus miembros- ha sido objeto de críticas por la aplicación de sanciones fuera del mandato del Consejo de Seguridad, ${ }^{24}$ pero esto es posible siempre y cuando no se violen acuerdos de comercio internacionales, como los acuerdos de la Organización Mundial del Comercio (OMC) (Portela, 2010; Eriksson, 2011; Giumelli, 2013; Giumelli, Hoffmann y Książczaková, 2020). Asimismo, y en vistas a la desigual implementación de las

20. Bajo la cual fueron designado Hamas y Hezbollah (10 de agosto de 1997). Se las llama foreign terrorist organizations (FTO).

21. Ser propiedad o controlada por, o a nombre de, un individuo o entidad ya listado; asistir, apoyar o proveer apoyo material, financiero o tecnológico a la ejecución de actos de terrorismo o a individuos o entidades ya listadas; estar asociado a individuos o entidades ya listadas. Terrorismo está definido como una actividad que involucra un acto violento o peligroso para la vida humana, propiedad o infraestructura, que está dirigido a intimidar o coaccionar a una población civil, o a influenciar la política de un gobierno a través de la intimidación o coacción, o a afectar la conducta de un gobierno a través de la destrucción masiva, el asesinato, secuestro o toma de rehenes.

22. Al presente hay dos tipos de listas: una cuya sanción es el congelamiento financiero y medidas reforzadas de cooperación policial y judicial, en la que se listan 15 personas y 21 organizaciones. Se incluye a Hamas y al «brazo armado del Hezbollah». Hamas ha cuestionado su permanencia en la lista $y$, ante la negativa del Consejo de retirarlo, ha iniciado un proceso ante el Tribunal General, cuyo fallo, inicialmente favorable a su pretensión, fue apelado por el Consejo. Otra lista tiene como sanción solo las medidas reforzadas y cuenta con 57 individuos y 47 entidades.

23. Directiva (UE) 2017/541 del Parlamento Europeo y del Consejo de 15 de marzo de 2017, Relativa a la lucha contra el terrorismo y por la que se sustituye la Decisión marco 2002/475/JAI del Consejo y se modifica la Decisión 2005/671/JAI del Consejo.

24. Y de la misma política de la Unión Europea respecto del respeto a los derechos humanos. Véase, por ejemplo, Orosan (2020). 
sanciones en los distintos Estados miembros, se ha argumentado que su grado de aplicación depende de la voluntad e involucramiento personal de las élites políticas (Druláková y Přikryl, 2016), fenómeno que se replica en otras partes del mundo.

Otros países tienen listados nacionales. Entre ellos se cuentan Israel, Rusia, Canadá, Australia, Países Bajos y Reino Unido. ${ }^{25}$ Muchos de estos listados son públicos y puede accederse a ellos en línea. ${ }^{26}$

En adición a este problema, eminentemente «público» y propio del sistema internacional, existe otro problema en la implementación de las sanciones, y es que son aplicadas en muchos casos por personas y entidades privadas (Bergstrom, Svedberg Helgesson y Morth, 2011; Svedberg Helgesson y Morth, 2016, 2018). Estas actúan movidas por el lucro, y necesitan tener una adecuada comprensión de los riesgos de determinadas transacciones. ${ }^{27}$ Asimismo, requieren contar con una adecuada publicidad en lo que respecta a las sanciones vigentes y su extensión, a fin de estar legalmente cubiertas en su accionar. La normativa no solo tiene que establecer explícita y taxativamente las obligaciones de los particulares en el análisis de riesgo y en la aplicación eventual de las sanciones que pudieren corresponder, sino también ser muy claras respecto de qué contrapartes resultan alcanzadas.

\section{La Argentina y el registro de personas y entidades vinculadas al terrorismo y su financiación}

La posición argentina frente al terrorismo está fuertemente signada por su historia reciente, la de los excesos del Estado en combatir a los grupos que ejercían la violencia política y a los que laxamente y con un fin derogatorio se denominaba «terroristas». Solo en este contexto se explican los esfuerzos discursivos y legislativos que tienen por objeto separar el reclamo social y la lucha contra gobiernos producto de rupturas del orden constitucional del verdadero terrorismo globalizado. ${ }^{28}$

Argentina condena al terrorismo en todas sus formas y manifestaciones y considera que sus actos constituyen una amenaza a la paz y seguridad internacionales y a

25. Estos dos últimos cuentan con un listado nacional, además de receptar el de la Unión Europea.

26. Véase, por ejemplo, la lista nacional neerlandesa: «National sanctionlist terrorism», Gobierno de Países Bajos, 11 de agosto de 2011, disponible en https://bit.ly/3zbxmSU.

27. Por ejemplo, una determinada transacción puede involucrar la remisión de dinero a un sujeto alcanzado por una sanción (Giumelly y Onderco, 2021).

28. Así, por ejemplo, el segundo párrafo del artículo 41 quinques del Código Penal actualmente vigente - pendiente de reforma - que, tras definir la «finalidad de terrorismo» como agravante de la pena de un delito cualquiera, aclara: «Las agravantes previstas en este artículo no se aplicarán cuando el o los hechos de que se traten tuvieren lugar en ocasión del ejercicio de derechos humanos y/o sociales o de cualquier otro derecho constitucional». ¡Como si fuera necesario! 
la dignidad humana, a la consolidación de la democracia y del desarrollo económico y social de las naciones. Considera que el terrorismo debe combatirse en el marco del Estado de derecho y del pleno respeto del derecho internacional, lo que exige una cooperación internacional orgánica y permanente, dentro del marco de las Naciones Unidas, de la Organización de los Estados Americanos ${ }^{29} \mathrm{o}$ del Mercosur, ${ }^{30}$ según el marco regional del que se trate.

La posición histórica de Argentina ha sido rechazar la adopción de sanciones unilaterales puesto que no tienen fundamento en el derecho internacional y la necesidad de respetar los mecanismos multilaterales. Por lo tanto, solo se consideran las designaciones como terroristas de individuos o entidades listados por el Consejo de Seguridad a través de resoluciones que los incluyan en un Comité de Sanciones relevante. Al mismo tiempo, el Decreto 1.521/2004 estableció un mecanismo para brindar publicidad a dichas resoluciones, atento las sanciones que conllevan.

A este respecto, el Decreto 918/2012, reglamentario de la 25.246, permite a la Unidad de Información Financiera (UIF) disponer el congelamiento administrativo de bienes o dinero de personas designadas por el Consejo de Seguridad de Naciones Unidas de conformidad con la Resolución 1.267 (1999) y sus sucesivas. ${ }^{31}$ También permite el congelamiento administrativo de activos vinculados con los delitos del artículo 306 del Código Penal, cuando estuvieran vinculados con la financiación del terrorismo. A su vez, una autoridad competente extranjera ${ }^{32}$ puede efectuar a la UIF un pedido de dicha medida fundado en la Resolución 1.373 (2001), el que podrá efectuarse previo un análisis de razonabilidad con consulta al Ministerio de Relaciones Exteriores y Culto y de Seguridad; de proceder la medida, se pondrá en conocimiento al juzgado competente. ${ }^{33}$ Este mecanismo permite a la Argentina dar acabado cumplimiento a las resoluciones del Consejo de Seguridad.

La UIF Argentina impuso, en 2018, sanciones financieras a los miembros del clan

29. La Convención Interamericana contra el Terrorismo (CICTE).

30. El Foro Especializado Terrorismo (FET).

31. El congelamiento administrativo debe ser comunicado inmediatamente al juez federal con competencia penal y se mantendrá en tanto la persona o entidad permanezca listada (artículo 11, Decreto 918/2012).

32. Las unidades de inteligencia financiera o equivalentes (definidas como una agencia central nacional responsable de recibir o, de estar permitido, requerir, analizar y compartir con las autoridades competentes información financiera concerniente a posibles operaciones de lavado de dinero o financiamiento del terrorismo) de 164 países se encuentran nucleados en un foro informal llamado el Grupo Egmont, fundado en Bruselas en 1995. A través del grupo, las agencias sistematizan y comparten información. Argentina preside el grupo al momento de escribir estas líneas.

33. Esta medida se mantendrá por seis meses, prorrogables por otros seis, al cabo del cual se levantará si no se ha recibido un pedido de asistencia judicial en materia penal que solicite su mantenimiento (artículo 16). 
Barakat, una red criminal de apoyo financiero de Hezbollah en la Triple Frontera dirigida por el ciudadano libanés Assad Ahmad Barakat, designado como financista del grupo terrorista por Estados Unidos. La medida marcó el precedente y fue la primera vez que Argentina impuso sanciones contra Hezbollah o alguien vinculado a la organización. En septiembre de ese año, la policía brasileña arrestó a uno de los miembros del clan, Assad Ahmad Barakat; en septiembre fue deportado a los Estados Unidos, y actualmente se encuentra a la espera de sentencia judicial. ${ }^{34}$

La intención política de Argentina de afianzar e incluso liderar la lucha contra el terrorismo y su financiación en el hemisferio, en línea con el liderazgo mostrado oportunamente en el proceso de creación del Comité Interamericano de Lucha contra el Terrorismo (CICTE) en el marco de la OEA, ${ }^{35} \mathrm{y}$ motivado por el hecho de haber sido víctima de dos cruentos atentados organizados por el terrorismo transnacional, ${ }^{36}$ la llevaron a participar del proceso de las Conferencias Ministeriales Hemisféricas de Lucha contra el Terrorismo, convocando a la segunda de ellas; y al mismo tiempo, a explorar la posibilidad de crear un mecanismo de designación propio de personas o entidades vinculadas al terrorismo.

\section{EI RePET}

El Registro de Personas y Entidades Vinculadas a Actos de Terrorismo y su Financiamiento (RePET) fue creado por el Decreto 489, del 16 de julio de 2019. Su creación fue anunciada públicamente durante la Segunda Conferencia Ministerial Hemisférica de Lucha contra el Terrorismo, por el entonces ministro de Justicia, Dr. Garavano.

Está diseñado como una modificación al Decreto 918, del 12 de junio de 2012, reglamentario «de las medidas y procedimiento previstos en el artículo 6 in fine de la Ley 26.734, sobre congelamiento administrativo de bienes vinculados a las actividades delictivas del artículo 306 del Código Penal, y el procedimiento de inclusión y exclusión de personas designadas en las listas elaboradas de conformidad con las Resoluciones pertinentes del Consejo de Seguridad de las Naciones Unidas» (artículo

34. George Chaya, «Argentina ha dado un paso adelante en la lucha contra el crimen y el terrorismo en Latinoamérica», Infobae, 20 de julio de 2019, disponible en https://bit.ly/3FC9gTM.

35. Argentina asumió un importante liderazgo en la lucha contra el terrorismo en el ámbito hemisférico cuando llamó a la Segunda Conferencia Especializada en la Lucha contra el Terrorismo, en el marco de la OEA. La Conferencia se desarrolló en noviembre de 1998 en la ciudad de Mar del Plata, y en ella se adoptó el Compromiso del mismo nombre. También se propició la creación de un organismo interamericano para combatir el terrorismo en el ámbito hemisférico, el cual dio origen al CICTE. El Comité Interamericano de Lucha contra el Terrorismo (CICTE) es el organismo especializado de la OEA y fue creado en la Asamblea General de la organización reunida en la Ciudad de Guatemala en julio de 1999 (Corach y Baizán, 2002: 45 y ss).

36. Conmemorándose el $25{ }^{\circ}$ aniversario del perpetrado contra la AMIA, el 18 de julio. 
1). Se incorpora a este como capítulo 6. De esta manera, se evita el engorroso procedimiento de aprobación de una ley del Congreso. ${ }^{37}$

El RePET funciona en el ámbito del Ministerio de Justicia y Derechos Humanos. ${ }^{38}$ No es el primer registro formado en relación a la comisión de un delito. En el ámbito del Ministerio de Justicia existe la Subsecretaría de Asuntos Registrales, dependiente de la Secretaría de Derechos Humanos y Pluralismo Cultural, que nuclea la Dirección Nacional del Registro Nacional de Reincidencia, el Registro Nacional de Sociedades y de Concursos y Quiebras, y el Registro Nacional de Datos Genéticos Vinculados a Delitos contra la Integridad Sexual, entre otros muchos con categoría de dirección nacional o general. ${ }^{39}$ De modo que la formación de un registro con los actos judiciales o administrativos vinculando a personas con determinados delitos no es una práctica desconocida en nuestro derecho.

\section{EI RePET en detalle}

La inscripción de una persona física o jurídica ${ }^{40}$ en el RePET procede por una de tres vías diferentes:

- Resolución judicial: Por haber recaído sobre ella una «resolución judicial o del Ministerio Público Fiscal que le impute o admita la formalización de una investigación por alguno de los delitos cometidos con la finalidad específica del artículo 41 quinquies o alguno de los delitos del artículo 306 del Código Penal de la Nación, o aquellos delitos equivalentes vigentes con anterioridad a la sanción de la Ley 26.734» (artículo 25, inciso a, Decreto 489/2019).

- Inclusión en los listados de la Resolución 1.267 (1999), sucesivas y concordantes del Consejo de Seguridad de la ONU (artículo 25, inciso b).

- Resolución de la Unidad de Información Financiera (UIF) disponiendo el congelamiento administrativo de activos.

37. Que aun en una temática más amable hubiera sido dificultoso para una propuesta del Ejecutivo, por el juego de las mayorías y el problema adicional de encontrarse en un año electoral.

38. Artículo 23, Decreto 489/2019. Más específicamente, en la Dirección Nacional del Registro de Reincidencia.

39. Dirección General del Registro de la Propiedad Inmueble de la Capital Federal (RPI); Dirección Nacional de los Registros Nacionales de la Propiedad del Automotor y de Créditos Prendarios (DNRPA); Dirección Nacional del Registro Nacional de Tierras Rurales; Dirección Nacional del Registro Nacional de Bienes Secuestrados y Decomisados durante el Proceso Penal; Dirección Nacional del Registro Único de Aspirantes a Guarda con Fines Adoptivos; Dirección Nacional del Derecho de Autor; Dirección Nacional del Registro Nacional de Empresas y Trabajadores de Control de Admisión y Permanencia (RENCAP).

40. «Persona humana, jurídica o entidad» (artículo 25, inciso a, Decreto 489/2019). 
Existe una cuarta manera de ser inscrito: a pedido de una UIF extranjera, a través de la UIF argentina, conforme y según el procedimiento del artículo 16 del Decreto 918/2012. ${ }^{41}$

Las formas de inscripción descriptas bajo los puntos b) y c) podrían calificarse de «administrativas». Indudablemente, la vía señalada bajo el punto b) es la más clara. Como hemos detallado más arriba, las personas o entidades vinculadas al terrorismo o su financiación se encuentran designadas conforme las dos listas del Comité de Sanciones creado por la Resolución 1.267 (1999) y modificado por las 1.989 (2111) y 2.253 (2015), es decir, la «Lista de Al-Qaida y EIIL (Daesh o ISIS)», ${ }^{42}$ y la «Lista del Talibán», que queda bajo el Comité Resolución 1.988 (2011). Las personas o entidades listadas también figuran en el llamado "Lista Consolidada del CSNU», ${ }^{43}$ reconocibles por sus prefijos: «QDe» para Al-Qaida e ISIL, y «Tae» para Talibán. Las personas y entidades listadas bajo otros comités no tienen la calificación de «terroristas», aunque una persona o entidad puede estar listada conforme los criterios de más de un comité. ${ }^{44}$ Los listados son receptados en el ordenamiento interno a través de la publicación en Boletín Oficial de una Resolución del Ministerio de Relaciones Exteriores y Culto,

41. Durante la elaboración de la norma, este supuesto era el que causaba mayor preocupación, ya que los otros estaban lo suficientemente acotados. Se veía en este supuesto particular una ventana a través de la cual podían filtrarse pedidos de países extranjeros para que la Argentina «designe como terroristas» — ¡no es la función de la norma! - a personas físicas o jurídicas motivadas en fines políticos, lo cual supondría desvirtuar el sistema. Además, existía el problema de la posible vinculación por parte de esos países de otras acciones, como por ejemplo negociaciones comerciales o acciones de cooperación en otros ámbitos, lo que crearía problemas de política exterior. En realidad, esta posibilidad ya existía desde la entrada en vigor del Decreto 918, es decir, ¡desde 2012!

42. «Comité del Consejo de Seguridad Establecido en virtud de las Resoluciones 1.267 (1999), 1.989 (2011) y 2.253 (2015) relativas al Estado Islámico en el Iraq y el Levante (Dáesh), Al-Qaida y las personas, grupos, empresas y entidades asociadas», Consejo de Seguridad de Naciones Unidas, 2021, disponible en https://bit.ly/349yrad.

43. «Lista consolidada del Consejo de Seguridad de las Naciones Unidas», Consejo de Seguridad de Naciones Unidas, 2021, disponible en https://bit.ly/3HmrdWW.

44. Durante el diseño de la plataforma, hubo un especial cuidado en los «filtros» que permitieran que solo los nombres de personas y entidades incluidos en regímenes relacionados con el terrorismo fueran «migrados» al RePET. En los primeros intentos, la totalidad de la lista consolidada — que abarca todos los regímenes - se migraba in totum al RePET, lo cual era incorrecto. Tras varias consultas, se logró que se implementara un filtro que se guiara por estos prefijos. Paradójicamente, en el instructivo en línea para la utilización del motor de búsqueda del RePET, se pone como ejemplo al funcionario norcoreano Son Jong Hyok, que no se encuentra en listado, por estar listado en el Comité de la Resolución 1.718 (2006) sobre la República Democrática Popular de Corea, relacionada con la proliferación de armas nucleares, biológicas y químicas por parte del Estado. «Instructivo para la verificación de personas y entidades posiblemente vinculadas con actos de terrorismo y su financiamiento», Unidad de Información Financiera, DTO 489/2019, disponible en https://bit.ly/3HaoK1A. 
como también de la publicación del enlace en su sitio web para su consulta en tiempo real (conforme Decreto 1.521, del 1 de noviembre de 2004, artículos 1 y 2).

Las sanciones son congelación de activos, ${ }^{45}$ prohibición de viajar (entendido como entrada y tránsito ${ }^{46} \mathrm{y}$ embargo de armas. La UIF es la encargada de disponer el congelamiento administrativo de bienes o dinero, mediante Resolución fundada (artículo 5, Decreto 918/12), una vez recibido el Reporte de Operación Sospechosa de Financiación del Terrorismo emitido por alguno de los sujetos obligados. ${ }^{47}$

La inclusión por resolución de UIF abarca a toda persona física o jurídica sobre la que haya ordenado el congelamiento administrativo de artículos previsto en el artículo 6, último párrafo de la Ley 26.734 (artículo 25, inciso c, Decreto 489/19). La UIF ejecuta la inscripción comunicando al Registro la novedad al mismo tiempo que la comunica al juez competente..$^{48}$ Asimismo, debe comunicar el levantamiento de la medida, en caso de error. ${ }^{49}$

En el caso del apartado c), es la propia UIF la que, por medio de una investigación propia, sea en el marco del análisis de un Reporte de Operación Sospechosa de Financiación del Terrorismo (artículo 15, inciso a) o a pedido de algún organismo público nacional (artículo 15, inciso b), y siempre en el marco del artículo 306 del Código Penal, decide dictar la resolución disponiéndolo. Este se pondrá en conocimiento de la autoridad solicitante, y del juez competente dentro de las 48 horas (artículo 15, párr. 5). Es esta la ocasión en que procede la comunicación al Registro a los fines de la inscripción (artículo 29). La medida se extenderá por seis meses prorrogables, al término de los cuales, de no mediar una resolución judicial en contrario, cesará.

Por oposición, la vía del inciso a) podría ser calificada de «judicial». La norma establece que se anotará en el Registro el testimonio de toda resolución judicial o dictamen del Ministerio Público Fiscal sobre una persona física o jurídica imputada

45. Establecidas en el párrafo 1 de la Resolución 1.452 (2002), en su forma enmendada por el párrafo 15 de la Resolución 1.735 (2006), renovadas en el párrafo 2 letra a) de la Resolución 2.253 (2015) y renovadas últimamente en el párrafo 1 letra a) de la Resolución 2.368 (2017).

46. Establecidas en el párrafo 1 letra b) de la Resolución 2.161 (2014), renovadas en el párrafo 2 letra b) de la Resolución 253 (2015) y renovadas últimamente en el párrafo 1 letra b) de la Resolución 2.368 (2017).

47. Que son definidos como «Sujetos obligados correspondientes a los sectores bancario, cambiario, del mercado de capitales y de seguros» (artículo 9, Decreto 918/12). Están obligados a verificar el listado del Consejo de Seguridad y efectuar, en el acto e inaudita parte, el congelamiento de los bienes o dinero involucrados en las operaciones mencionadas, con informe inmediato a la UIF. Las obligaciones de estos sujetos están adecuadamente definidas en Resoluciones de la UIF.

48. Comunicación obligatoria según el artículo 11 del Decreto 918/12. El juez efectuará el correspondiente examen de la legalidad de la medida.

49. «Afecta a una persona física o jurídica o a una entidad diferente a la designada por las Naciones Unidas». 
de un delito cometido con la finalidad específica del artículo 41 quinquies del Código Penal —esto es, «cuando alguno de los delitos previstos en este Código ${ }^{50}$ hubiere sido cometido con la finalidad de aterrorizar a la población u obligar a las autoridades públicas nacionales o gobiernos extranjeros o agentes de una organización internacional a realizar un acto o abstenerse de hacerlo»- ${ }^{51}$ Asimismo, cuando se tratase de alguno de los delitos del artículo 306 del mismo Código, es decir, aquellos que acciones de financiamiento o apoyo al terrorismo. ${ }^{52}$

La norma (artículo 48, Decreto 489/2019) continúa detallando con mayor especificidad qué resoluciones judiciales o dictámenes del Ministerio Público Fiscal ameritan la inscripción. Son aquellas dictadas en los términos del artículo 282 (citación del

50. Aquí ha pecado por exceso nuestro legislador, ya que internacionalmente los delitos con finalidad de terrorismo deben ser «delitos graves contra la vida o la propiedad». Véase, para una acertada discusión sobre las limitaciones conceptuales del sistema del artículo 41 quinquies del Código Penal, Ricciardi (2013: 61).

51. En estos casos, «la escala se incrementará en el doble del mínimo y el máximo». La norma hace la salvedad de que «las agravantes previstas en este artículo no se aplicarán cuando el o los hechos de que se traten tuvieren lugar en ocasión del ejercicio de derechos humanos y/o sociales o de cualquier otro derecho constitucional», lo cual parece suficiente - e innecesario- a fin de aclarar que la acción típica no constituye «delito de terrorismo», pero deja la duda sobre si igualmente se la considera un delito común, a pesar de la «ocasión».

52. Introducido por la Ley 26.734, reza: «1. Será reprimido con prisión de cinco (5) a quince (15) años y multa de dos (2) a diez (10) veces del monto de la operación, el que directa o indirectamente recolectare o proveyere bienes o dinero, con la intención de que se utilicen, o a sabiendas de que serán utilizados, en todo o en parte: a) Para financiar la comisión de un delito con la finalidad establecida en el artículo 41 quinquies; b) Por una organización que cometa o intente cometer delitos con la finalidad establecida en el artículo 41 quinquies; c) Por un individuo que cometa, intente cometer o participe de cualquier modo en la comisión de delitos con la finalidad establecida en el artículo 41 quinquies. 2. Las penas establecidas se aplicarán independientemente del acaecimiento del delito al que se destinara el financiamiento $\mathrm{y}$, si este se cometiere, aun si los bienes o el dinero no fueran utilizados para su comisión. 3. Si la escala penal prevista para el delito que se financia o pretende financiar fuera menor que la establecida en este artículo, se aplicará al caso la escala penal del delito que se trate. 4. Las disposiciones de este artículo regirán aun cuando el ilícito penal que se pretende financiar tuviere lugar fuera del ámbito de aplicación espacial de este Código, o cuando en el caso del inciso b) y c) la organización o el individuo se encontraren fuera del territorio nacional, en tanto el hecho también hubiera estado sancionado con pena en la jurisdicción competente para su juzgamiento». 
imputado), ${ }^{53} 283$ (orden de detención), ${ }^{54} 294$ (indagatoria), ${ }^{55}$ autos de procesamiento, de prisión preventiva, de rebeldía y paralización de causa, de elevación a juicio, sentencias condenatorias, absolutorias o asimilables tanto del Código Procesal Penal de la Nación (Ley 23.984) como del Código Procesal Penal Federal, como también cualquier resolución que ponga fin a su situación procesal.

Como se ve, las resoluciones previstas revisten la suficiente gravedad como para ameritar la inscripción en el Registro. Por otra parte, aquella persona sobre la cual hubiera recaído las mismas habrá sido sujeto de embargo o inhibición de bienes (artículo 518 Código Procesal Penal), de prohibición de viaje (implícito en la disposición del artículo 310, párr. 1) y también del embargo de armas. El efecto adicional de la inscripción será el del artículo 30, Decreto 489/19, y hace al congelamiento de activos si no se hubiera efectuado con anterioridad.

Finalmente, existe, como dijimos, una cuarta vía, y es la de inscripción por pedido de autoridad extranjera. Esta tiene su antecedente directo en las solicitudes de congelamiento procedentes de autoridades competentes extranjeras, ${ }^{56}$ que trata el

53. «Cuando el delito que se investigue no esté reprimido con pena privativa de la libertad o parezca procedente una condena de ejecución condicional, el juez, salvo los casos de flagrancia, ordenará la comparecencia del imputado por simple citación. Si el citado no se presentare en el término que se le fije ni justificare un impedimento legítimo, se ordenará su detención». Aquí nuevamente vemos la inclusión de delitos de pena leve (no privativa de la libertad o pasible de ejecución condicional) que resultaría contraria al criterio internacional para los delitos de terrorismo. Sin embargo, la orden de detención que pudiera dictarse por la incomparecencia del imputado ante la simple citación podría justificar la inclusión en el Registro.

54. «Salvo lo dispuesto en el artículo anterior, el juez librará orden de detención para que el imputado sea llevado a su presencia, siempre que haya motivo para recibirle indagatoria. La orden será escrita, contendrá los datos personales del imputado u otros que sirvan para identificarlo y el hecho que se le atribuye, y será notificada en el momento de ejecutarse o inmediatamente después, con arreglo al artículo 142».

55. «Cuando hubiere motivo bastante para sospechar que una persona ha participado en la comisión de un delito, el juez procederá a interrogarla; si estuviere detenida, inmediatamente, o a más tardar en el término de veinticuatro (24) horas desde su detención. Este término podrá prorrogarse por otro tanto cuando el magistrado no hubiere podido recibir la declaración, o cuando lo pidiere el imputado para designar defensor».

56. La «naturaleza» de la «autoridad competente extranjera» no está explicitada y, a primera vista, esto es correcto, puesto que cada ordenamiento jurídico nacional señalará cuál es. Sin embargo, ante la extrema sensibilidad de un listado de acceso público en el que las personas incluidas se considera que tienen vinculaciones con el terrorismo o su financiación, hacen que sea necesario dedicar un mínimo de análisis a esta cuestión. No parece generar inconvenientes conceptuales el pedido proveniente de una autoridad judicial extranjera, que bien podría enmarcarse dentro del artículo 67 y ss. de la Ley 24.767 de Cooperación Internacional en Materia Penal. Un poco más problemático puede resultar el pedido de una UIF extranjera, ya que se trata de organismos autárquicos designados por el Ejecutivo respectivo; en este caso, existen ámbitos institucionales de cooperación como el GAFI (es un organismo intergu- 
artículo 16 del Decreto 918/12. Es curioso que las autoridades nacionales hayan sido plenamente conscientes de este mecanismo, vigente desde 2012, solo en ocasión de la creación del RePET en 2019. La norma citada prevé un procedimiento de evaluación que incluye un análisis de razonabilidad por la UIF con consulta inmediata al Ministerio de Relaciones Exteriores y al de Seguridad. Si se resuelve su procedencia, se dicta una resolución conforme al artículo 5 y notifica al sujeto obligado (artículo 6), que procederá a implementar la medida (artículo 7) y, eventualmente, se notifica a los organismos reguladores (artículo 8), además de notificar a aquella a la autoridad que requirió el congelamiento. Puesto que el congelamiento es en definitiva ordenado por la UIF por medio de una resolución propia, es en ocasión de su dictado que se comunica al Registro para su inscripción.

\section{Conclusiones}

Conceptualmente, el RePET no es un mecanismo de designación, aunque su efecto es la «formación de un listado» de personas vinculadas a un acto de terrorismo o su financiación..$^{57}$ En efecto, la norma no crea un marco legal en el cual una autoridad, judicial o del Ejecutivo, se ve investida de la facultad de dictar una disposición judicial o administrativa especial que «designa» a una persona como «terrorista», o que la considera vinculada a un acto de este tipo..$^{58}$ Tampoco establece una resolución judicial o acto administrativo especial de «designación», en el marco de un proceso en

bernamental cuyo propósito es el desarrollo y la promoción de políticas) y el Grupo Egmont (una red internacional de diversas UIF cuyo objetivo es ampliar, sistematizar y mejorar la eficacia de la cooperación internacional en el intercambio recíproco de información de inteligencia financiera, compartir conocimientos y experiencias, ofrecer capacitación para incrementar la eficiencia de las UIF, incrementar el uso de tecnología y fomentar la autonomía operativa de las UIF). Una UIF extranjera puede solicitar a la UIF argentina una medida de congelamiento de activos o aportar información para que la misma proceda a tomar dicha medida en una investigación propia. La credibilidad de este pedido o información es parte esencial de análisis de razonabilidad que el ordenamiento pone bajo responsabilidad de la UIF. En cuanto a la intervención del MREC, es de suponer que se orientará hacia las probables consecuencias de la medida propuesta en la política exterior y seguridad de la Nación. Finalmente, el pedido de autoridades o tribunales especiales constituidos sin respetar el derecho internacional y el derecho internacional de los derechos humanos podrá ser rechazado por resolución fundada después del procedimiento de evaluación previsto por la norma.

57. Lo cual nos remite mentalmente a los listados del Consejo de Seguridad de Naciones Unidas, que son «constitutivos» de la calificación de «terrorista».

58. En agosto, a su vez, Paraguay siguió el ejemplo por medio de un Decreto Presidencial, designando como «grupos terroristas globales» a Hezbollah y Hamas — junto con ISIS y Al-Qaeda-, disponiendo medidas para impedir sus actividades de lavado de dinero y financiamiento. Este acto constituye una «designación» en un sentido más directo que en el caso argentino, en tanto se trata de un acto ad hoc de una autoridad del Estado. 
curso. Simplemente se limita a «recopilar» actos judiciales o administrativos de fuentes diversas que disponen medidas contra personas físicas o jurídicas en relación a su vinculación a este tipo de actos u organizaciones. Esto no quita que, casi sin excepción, la prensa, y curiosamente parte del ambiente académico, ${ }^{59}$ se refieran reiteradamente al mismo como «mecanismo de designación», incluyendo la «designación de Hezbollah» como grupo terrorista en el mismo acto; ${ }^{60}$ esto resulta particularmente desafortunado, no solo porque malinterpreta por completo su naturaleza y alcances, sino porque niega su carácter de ingenioso compromiso. ${ }^{61}$ Resulta, en cambio, un mecanismo útil para sistematizar el cumplimiento de las Resoluciones del Conejo de Seguridad de Naciones Unidas y de las medidas de los Comités de Sanciones, al tiempo que es un medio para dar publicidad y transparencia a los procedimientos judiciales y de la UIF en cuyo marco se ordenan congelamientos de activos. Al mismo tiempo, constituye un reaseguro a los particulares, quienes son los verdaderos responsables de implementar las sanciones en primera instancia, informándoles adecuadamente sobre qué sujetos deben cumplir las obligaciones correspondientes.

\section{Referencias}

Bergstrom, Maria, Karin Svedberg Helgesson y Ulrika Morth (2011). «A new role for for-profit actors? The case of anti-money laundering and risk management». Journal of Common Market Studies, 49 (5): 1.043-1.064. DOI: 10.1111/j.1468-5965.2010.02167.x.

Bermejo García, Romualdo (2013). "Algunos comentarios sobre las sanciones del Consejo de Seguridad y la protección de derechos humanos: Luces y sombras». Revista Electrónica Latinoamericana, 7 (2): 16-40. Disponible en https://bit. ly/3pCORZb.

59. Patricia Kreibohm, «La polémica por el decreto presidencial para declarar a Hezbollah como grupo terrorista», Boletín del Instituto de Relaciones Internacionales de la Universidad Nacional de La Plata, julio de 2019, disponible en https://bit.ly/3qzHnoL.

6o. Véase, por ejemplo, «Macri firmó el decreto para declarar a Hezbollah como organización terrorista», Página/12, 17 de julio de 2019, disponible en https://bit.ly/3EClZV9; Martín Torino, «Macri decreta a Hezbollah como organización terrorista», El Cronista, 11 de julio de 2019, disponible en https:// bit.ly/3EAUE5u.

61. Esta errónea interpretación del instituto puede adjudicarse a simple ignorancia o incluso a la mala fe, ya que existía la intención de la oposición política al gobierno del ingeniero Mauricio Macri de resaltar su -en opinión de esa vertiente política - incondicional alineación con la política estadounidense, aun en desmedro del tradicional respeto por los derechos humanos que informa la política interna y exterior argentina. Volvemos al involucramiento de las élites políticas en la lucha contra el terrorismo del que hablaban Radka Druláková y Pavel Přikryl. Véase, por ejemplo, «Rechazo al decreto de Macri que declara a Hezbollah como agrupación terrorista», Página/12, 17 de julio de 2019, disponible en https:// bit.ly/3FAOZxG. 
Biersteker, Thomas J., Sue E. Eckert y Marcos Tourinho (2016). Understanding United Nations targeted sanctions. Cambridge: Cambridge University Press.

Byers, Michael (editor) (2001). The role of law in international politics: Essays in international relations and international law. Oxford: Oxford University Press.

Chiletro, Franco y Tamara G. Quiroga (2018). «La ONU». En Sofía Danessa (coordinadora), Guía de derecho internacional público. Buenos Aires: Educa.

CoHen, David S. y Zachary K. Goldman (2019). «Like it or not, unilateral sanctions are here to stay». AJIL Unbound, 113: 146-151. DOI: 10.1017/aju.2019.24.

NRC, Consejo Noruego para los Refugiados, y OCHA, Oficina de Naciones Unidas para la Coordinación de Asuntos Humanitarios (2018). Principles under pressure: The impact of counterterrorism measures and preventing/countering violent extremism on principled humanitarian action. Disponible en https://bit.ly/3FDRzmy.

CoRACH, Carlos y Mario Baizán (2002). La respuessta argentina frente al terrorismo. Buenos Aires: FUPOMI.

Cortright, David y George A. López (1995). Economic sanctions: Panacea or peacebuilding in a post-Cold War World. Boulder: Westview.

-. (2000). The sanctions decade: Assessing UN strategies in the 1990s. Boulder: Lynne Rienner.

-. (2002). Smart sanctions: Targeting economic statecraft. Lanham: Rowman \& Littlefield.

Druláková, Radka y Pavel Přikryl (2016). «The implementation of sanctions imposed by the European Union: A comparison of the Czech and Slovak republics' compliance». Central European Journal of International \& Security Studies, 10 (1): 134-16o. Disponible en https://bit.ly/3ECnxyr.

Eriksson, Mikael (2011). Targeting peace: Understanding UN and EU targeted sanctions. Farnham: Ashgate.

GiUmelLI, Francesco (2011). Coercing, constraining and signalling: Explaining UN and EU sanctions after the Cold War. Colchester: ECPR Press.

-. (2013). The success of sanctions: Lessons learned from the EU experience. Farnham: Ashgate.

Giumelli, Francesco, Fabian Hoffmann y Anna Książczaková (2020). «The when, what, where and why of European Union sanctions». European Security, 30 (1): 1-23. DOI: 10.1080/09662839.2020.1797685.

Giumelli, Francesco y Michal Onderco (2021). «States, firms, and security: How private actors implement sanctions, lessons learned from the Netherlands». European Journal of International Security, 6 (2): 190-209. DOI: 10.1017/eis.2020.21.

Hudson, Andrew (2007). "Not a great asset: The UN Security Council's regime: Violating the human rights». Berkeley Journal of International Law, 25 (2). DOI: 10.15779/Z38BD38. 
KatZMAn, Kenneth (2020). US-Iran conflict and implications for US Policy. Washington D. C. Disponible en https://bit.ly/3qzHiBt.

LeVITT, Matthew (2021). Hezbollah's regional activities in support of Iran's proxy networks. Washington D. C. Disponible en https://bit.ly/3Hliqy2.

Orosan, Alina (2020). "UNSC sanctions vs. European Convention on human rights». Disponible en https://bit.ly/3Hliz4y.

Portela, Clara (2010). European Union sanctions and foreign policy: When and why do they work? Nueva York: Routledge.

Ricciardi, Martín G. (2013). "Análisis de las agravantes del art. 41 quinquies incorporado por la Ley 26.734». Intercátedras, 1 (1): 61-76. Disponible en https://bit. ly/3 3 HiOwRb.

Svedberg Helgesson, Karin y Ulrika Morth (2016). «Involuntary public policy: Making by for-profit professionals: European lawyers on anti-money laundering and terrorism financing». Journal of Common Market Studies, 54 (5): 1.216-1.232. DOI: $10.1111 / \mathrm{jcms} .12356$.

-. (2018). «Client privilege, compliance and the rule of law: Swedish lawyers and money laundering prevention». Crime, Law and Social Change, 69 (2): 227-248. DOI: $10.1007 / \mathrm{s} 10611-017-9753-8$.

Tsebelis, George (1990). «Are sanctions effective? A game-theoretic analysis». Journal of Conflict Resolution, 34 (1): 3-28. DOI: 10.1177/0022002790034001001.

\section{Sobre el autor}

Fernando Rolandelli es abogado de la Universidad Católica Argentina Santa María de los Buenos Aires, Argentina. Doctor en Derecho Internacional Privado de la Universidad Notarial de La Plata, Argentina. Diplomado en International Environmental Law, Instituto de las Naciones Unidas para Formación Profesional e Investigaciones, Ginebra. Profesor titular de Derecho Internacional Público de la Universidad Católica Argentina Santa María de los Buenos Aires. Miembro del Servicio Exterior de la Nación de la República Argentina. Su correo electrónico es finargil@ gmail.com. (D) https://orcid.org/oooo-0001-9500-1978. 
La Revista Tribuna Internacional busca fomentar la reflexión, el debate, el análisis y la comunicación pluralista y con rigor científico en las áreas del derecho internacional público, derecho internacional privado, relaciones internacionales y derecho internacional de los derechos humanos. Los artículos y ensayos son seleccionados mediante revisión de pares externos a la Facultad de Derecho de la Universidad de Chile. Se reciben trabajos en castellano y en inglés.

EDITOR GENERAL

Luis Valentín Ferrada Walker

SITIO WEB

tribunainternacional.uchile.cl

CORREO ELECTRÓNICO

revistatribuna@derecho.uchile.cl

LICENCIA DE ESTE ARTÍ́CULO

Creative Commons Atribución Compartir Igual 4.o Internacional

La edición de textos, el diseño editorial

y la conversión a formatos electrónicos de este artículo

estuvieron a cargo de Tipográfica

(www.tipografica.io) 